\title{
Flood risk assessment with the implementation of a two-dimensional hydraulic model in a floodplain catchment
}

\author{
Z. Alsaqqaf \& H. Zhang \\ Centre for Infrastructure Engineering and Management, \\ Griffith School of Engineering, Griffith University, Australia
}

\begin{abstract}
This study develops a flood risk assessment method using a temporal analysis of hydraulic data of a floodplain catchment in extreme weather event. The research includes two phases. In Phase 1: a 2-dimensional hydraulic model in the lower Nerang River on the Gold Coast, Australia is established, which provides accurate estimations of the water level and flow. Then, in Phase 2, a risk assessment model is developed to evaluate the risk due to the floods. The risk model consists of four indices: Vulnerability $(\beta)$, Reliability $(\alpha)$, Resiliency $(\gamma)$ and Flood Risk Index (FRI). These indices have the capability of representing the hydraulic system's behaviour from the risk incurred. Ultimately, the risk assessment will enhance the decision making process to achieve a sustainable and more resilient infrastructure, as well as give implications on the optimization of engineering planning and design.

Keywords: flood risk assessment, hydraulic simulation, vulnerability, reliability, residency.
\end{abstract}

\section{Introduction}

The rapid change in patterns and frequencies of the weather conditions, have strained the resiliency of the current engineering infrastructure, especially, in an extreme event. These changes introduce a unique challenge for the current 
infrastructure in terms of capacities and adaptive measures. Accordingly, it is essential for a sensitive asset to be assessed and analysed to whether it can cope with such an impact.

Increased frequencies of storms and sea level rises have been observed and monitored in Australia [1]. It results in the increase of floods in many areas that are already prone to flood. Therefore, it is important for decision makers and planners to understand these rapid changes, and try to adapt it, especially for engineering infrastructures.

2-dimensional hydraulic model has been used to predict shallow water flooding in urban areas [2]. A satisfactory result was obtained by applying this strategy to the Fuji River basin in Japan. It provided information for the real-time operations of rescue and evacuation routes in the municipal region during the flooding event. It was also able to predict natural variations in stream flow that resulted from changes in human actions and land use [3]. This type of simulation would be a useful tool in the development of the strategic management plan for the Nerang floodplain catchment area. It would allow planners to go beyond water levels and landforms and develop strategies for rescue and recovery.

For the flood risk assessment, Simonovic and $\mathrm{Li}$ in 2003 [4] combined the system dynamics and performance assessment methods to evaluate the infrastructure's reliability and behaviour. However, the current methodology of this study is implementing a hydraulic simulation as an operational method in replacement of system dynamics to overcome the ambiguity and subjectivity of the hydraulic results $[5,6]$, which may affect the integrity and accuracy of the risk assessment model.

The purpose of this study is to develop an advanced methodology to evaluate the performance of a floodplain catchment; in a way, to depict the behaviour of the catchment under a flood event temporally. The paper will undertake a case study by applying a 2-dimensional hydraulic model to simulate a flood event in a study domain; then, will conduct a risk model that depends on the output of the hydraulic model to analyse and assess the performance of the catchment.

\section{Research domain}

The study domain of this research is located in the lower Nerang Catchment on the Gold Coast city, Australia. The catchment is a vast area with many changing local conditions within its boundaries. Also, it has been known for its tourist attraction. Therefore, high dense of populated sector can, as well as there are many man-made channels, riverbanks and lakes scattered around the research domain as can be observed in figure 1. Generally, this research domain has been chosen, due to the availability of topography as well as hydrological data. 


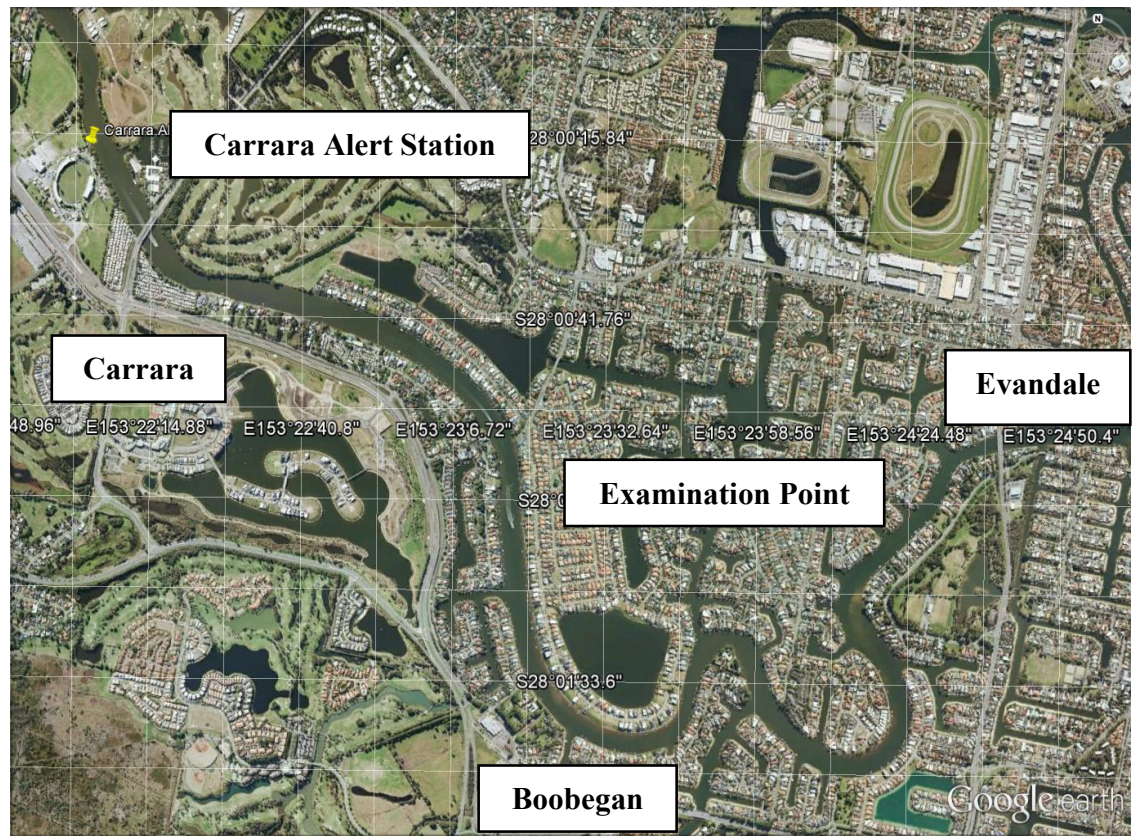

Figure 1: $\quad$ Lower Nerang catchment on the Gold Coast, Australia [7].

\section{Methodology framework}

The study employs a bilateral approach that integrates a hydraulic model and risk assessment model as a solid evaluation system. It aims to provide an accurate estimation of the driving risk element: water level, followed by a risk assessment model that offers a thorough evaluation of the study domain.

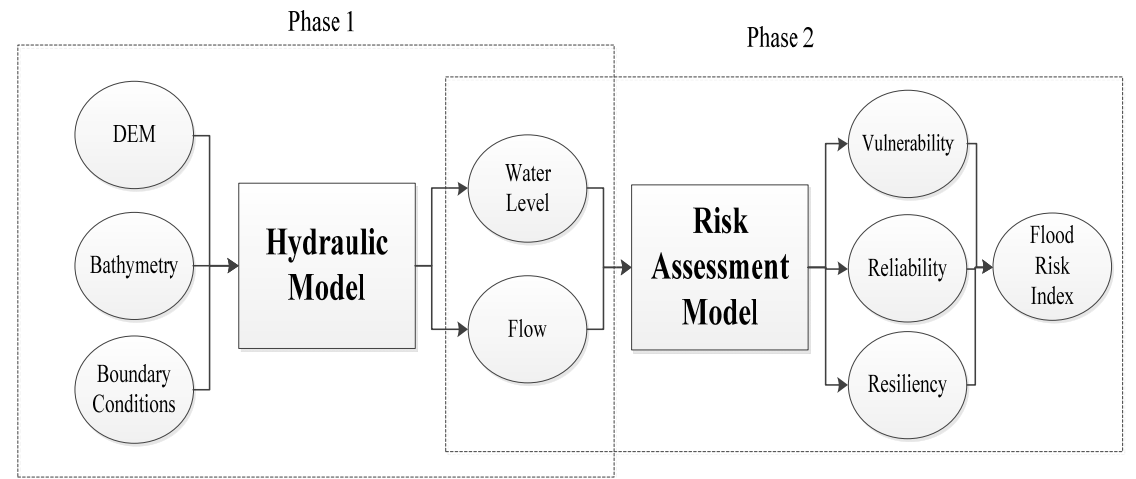

Figure 2: $\quad$ Methodology framework. 
In fact, this approach consists of two phases as seen in figure 2: In phase 1, a 2-dimensional hydraulic model that will be established. The inputs of the model include the bathymetry, flow data and tidal elevations at the boundaries. The outputs of the hydraulic model include temporal water levels, flows and velocities. These outputs will be as an input for the risk assessment model in phase 2. In this phase, the risk model employs performance assessment indicators: reliability, vulnerability, resiliency and Flood Risk Index. The first three indicators were developed by Hashimoto et al. [8], and FRI was developed by Zongxue et al. [9]. The following section will illustrate the two phases in details, as well as their actual application.

\section{Hydraulic model}

\subsection{Model setup}

The development of an appropriate hydraulic model will play an important role in the ability of design engineers and planners to meet the needs of the community in flood protection in the Nerang floodplain catchment. Thus, DHI MIKE21 software was used [10], to simulate the water levels and flow conditions.

The topography information is shown in figure 3. It has a grid size of 30meter and 77 time steps. In the area, there are three boundaries: one in the west that illustrates flow coming from upstream in Carrara, south from the Boobegan

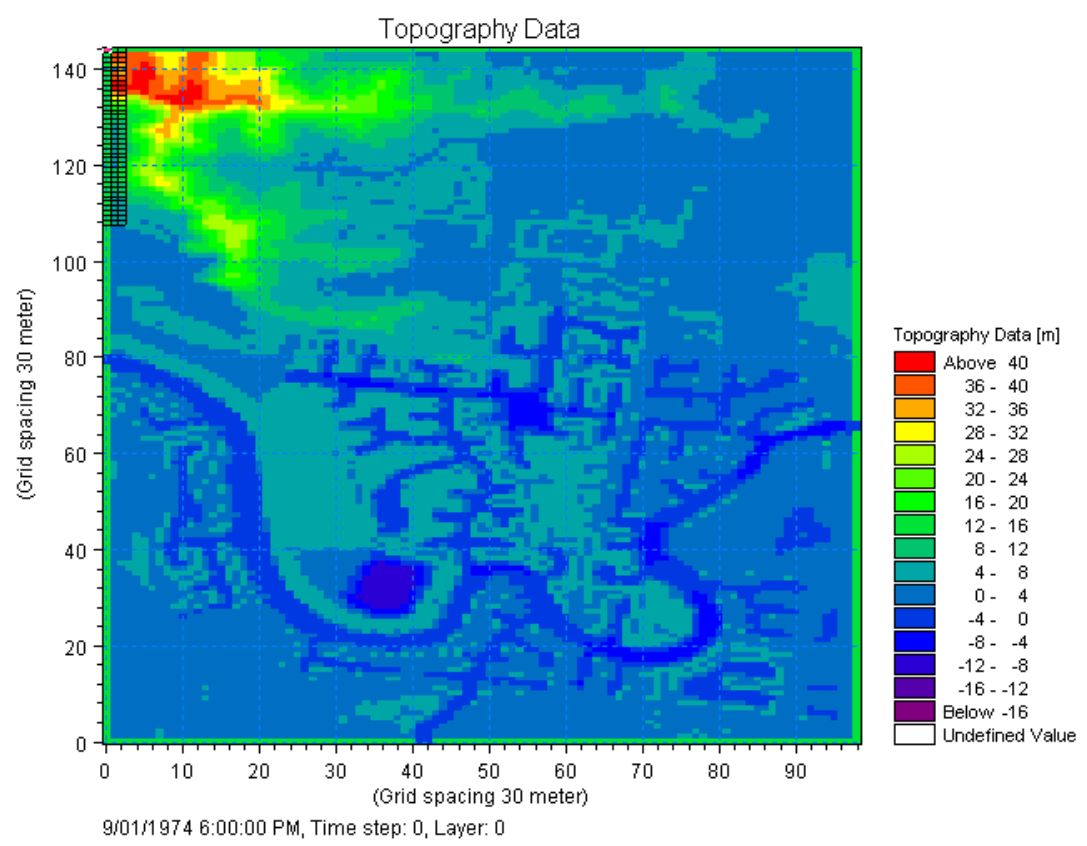

Figure 3: Topography data for the study domain. 
creek and downstream east in Evandale. These three locations have measurement stations in place that is managed by the Department of Environment and Resources Management, and the Bureau of Meteorology of the Australian Government in Queensland.

\subsection{Model calibration}

In hydraulic modelling, the bed resistance or roughness value plays an important role in calibrating the model. The smaller the resistance value is, the higher the bed resistance will be. As a result, simulated water can be adjusted to approximately match the actual measured water level.

In this study, a comparison between the measured and the simulated water level in Carrara Alert Station; (153 $\left.22^{\prime} 04^{\prime \prime}, 28^{\circ} 00^{\prime} 18^{\prime \prime}\right)$, is shown in figure 4. The calibration period was the same as the simulation period which was from 3105-2012 to 03-05-2012. A bed resistance of $32\left(\mathrm{~m}^{1 / 3} / \mathrm{s}\right)$ has achieved a correlation of $90 \%$ between the measured and simulated water level.

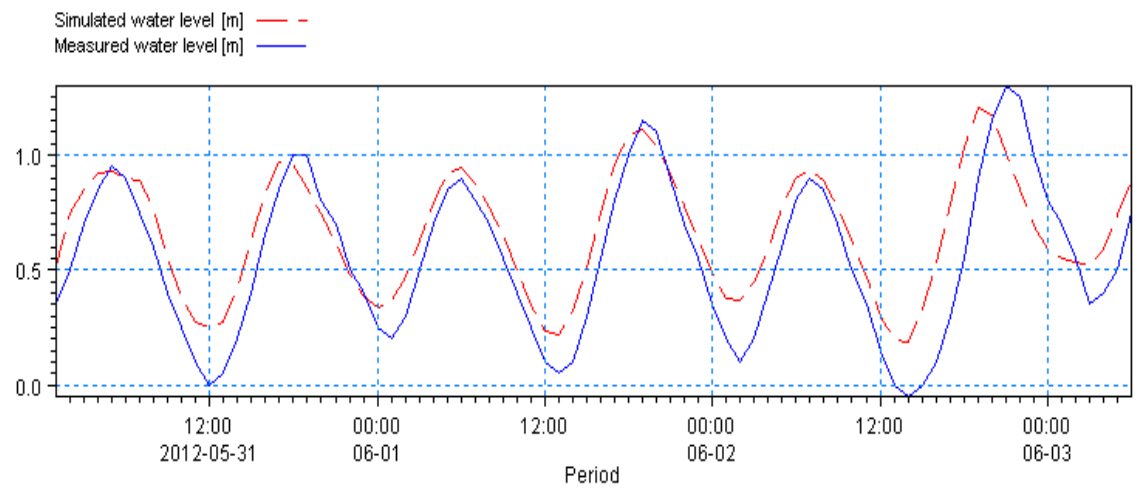

Figure 4: Calibration of the hydraulic model.

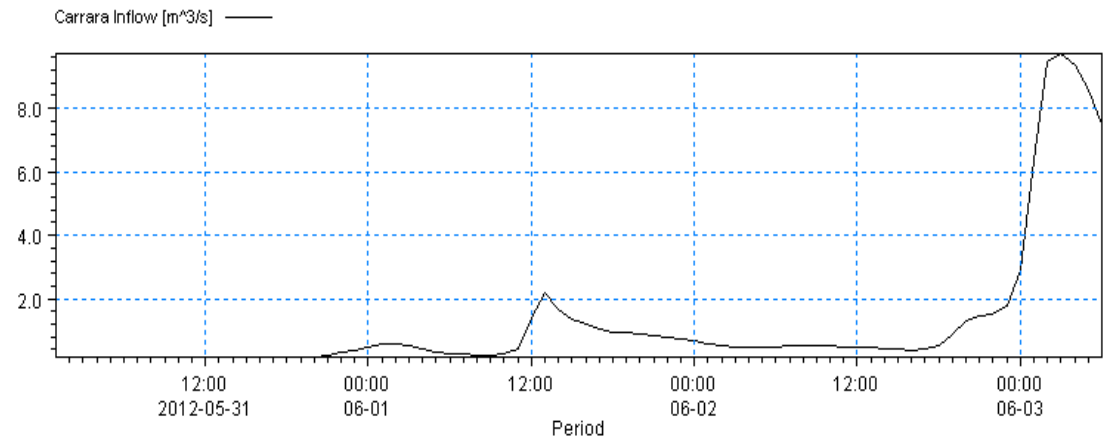

Figure 5: $\quad$ Boundary condition at Carrara. 


\subsection{Simulations}

This study has applied a simulation period of this model carried for three stormy days. This simulation period has the characteristics of higher water levels than average (above $0.6 \mathrm{~m}$ AHD). Also, there were three boundary conditions as their locations illustrated in figure 1 that have been assigned to the simulation: discharge $\left(\mathrm{m}^{3} / \mathrm{s}\right)$ boundary in Carrara, and level boundaries (meters) for both Boobegan Creek and Evandale. Figure 5 illustrates a sample inflow boundary condition in Carrara that was used in the simulation.

In addition, in this simulation a hydraulic warm-up period has been conducted for 5 days before applying the main model. However, the results shown in this paper only presents the main simulation period. Table 1 shows basic simulation parameters that have been used in the simulation.

Table 1: $\quad$ Simulation parameters.

\begin{tabular}{l|l}
\hline Parameter & Value \\
\hline Simulation Period (days) & 31-05-2012 1:00:00am (start) \\
03-06-2012 1:00:00am (end) \\
No. of time steps (seconds) & 3 \\
Time step Interval (seconds) & 92400 \\
Bed Resistance (m $1 / 3 / \mathrm{s})$ & 32 \\
\cline { 2 - 2 }
\end{tabular}

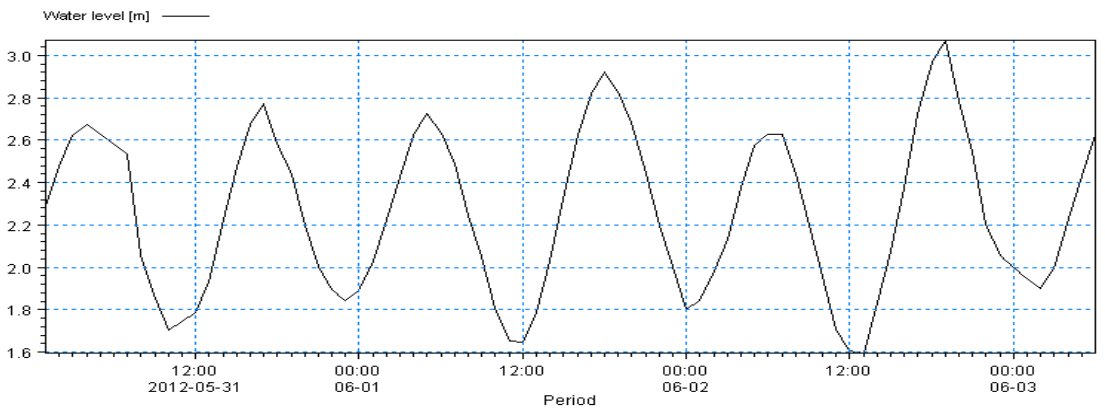

Figure 6: $\quad$ Extracted water levels.

Generally, the input of this phase consists of hydrology conditions that are related homogeneously to the catchment at the simulation period or simulated event that is being examined. Nevertheless the output of the model contains simulated water levels as can be illustrated in figure 7 spatially. As far as the current paper, a point in the on the river bank has been chosen to be examined. This point is on (153 ${ }^{\circ} 24^{\prime} 32.94 ", 28^{\circ} 01^{\prime}$ 02.01") longitude and latitude respectively as shown in figure 1 . And a time series of water level has been extracted and loaded as an input to the risk assessment model as seen in figure 6 . 


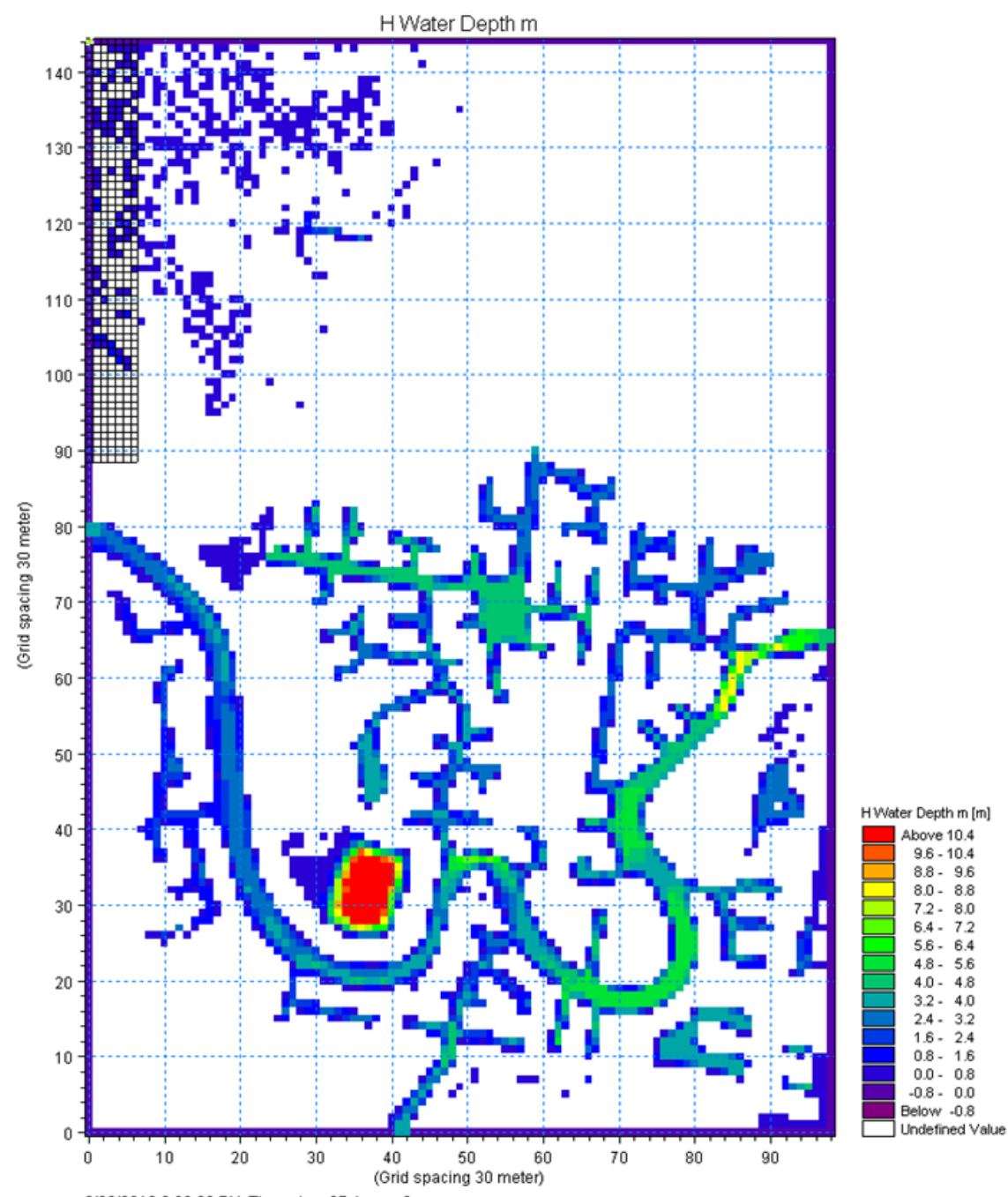

Figure 7: Output results of water depth.

\section{Risk assessment model}

In phase 2, the indicators of: reliability, vulnerability, resiliency, and FRI will be applied following the pervious study [11]. These indicators assess the system's behaviour upon a historical flood event.

In this paper the input of the risk model is the output of the hydraulic model, which i.e. the simulated water level and flow. Then, the performances indicators were measured and the risk model was illustrated from the corresponding output 
of phase one. Every performance indicator has a representative statistical equation that was described and explained in details in the last paper [11].

Therefore, the output of the model that is represented by the four indicators have been deduced and illustrated temporally as shown in figure 8 .

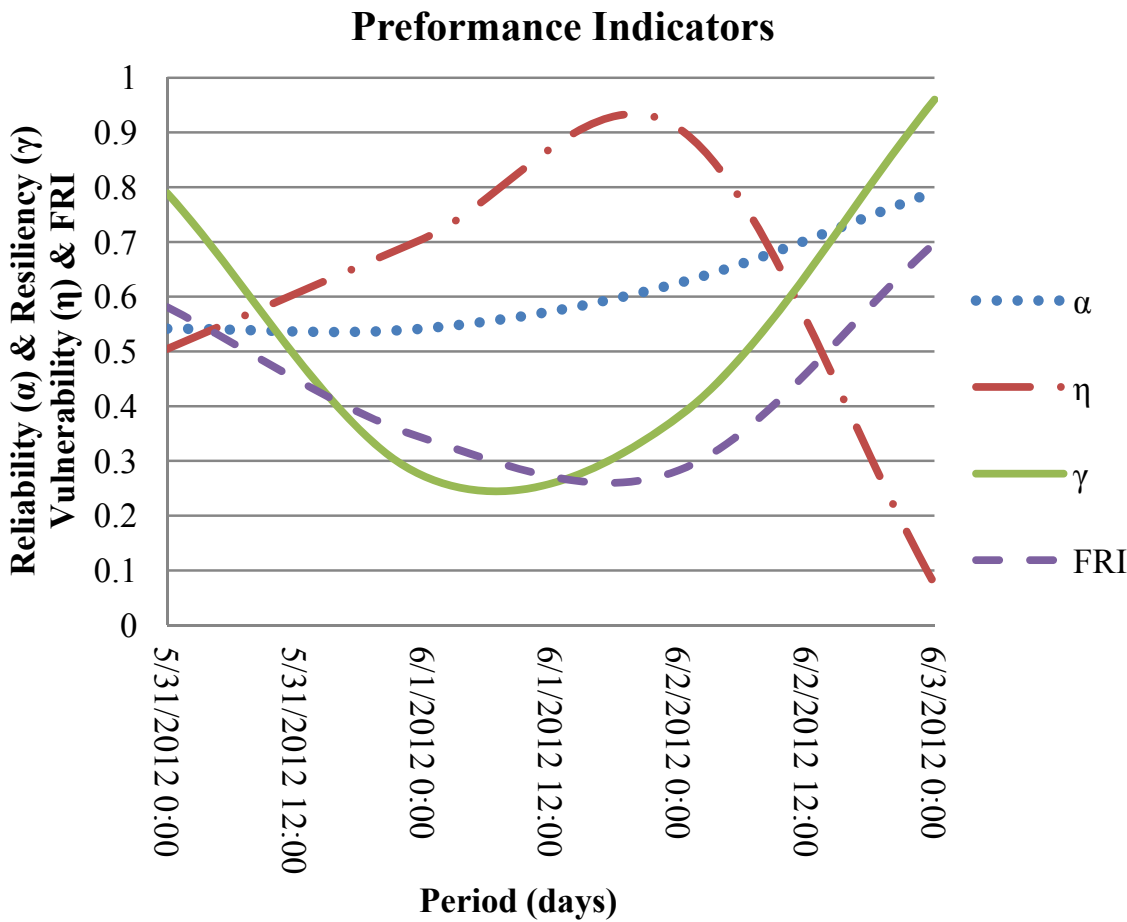

Figure 8: Measured performance indicators: reliability, resiliency, vulnerability and FRI.

The indicators in this risk model have behaved as expected. It profoundly proved a homogenous correlation between the two phases; in a way of representing the temporal fluctuation of the flow and water level in a simulated event. Nevertheless, the indicators have shown common volatility behaviour. Noticeably, there was an inverse relationship between the reliability and vulnerability in a high water level event. Also, there was a proportional relationship between the resiliency and reliability. In contrary, the longer the vulnerability indicator persisted the lower the resiliency indicator replicated.

The intrinsic value of the FRI indicator presents on the combination of the three indicators. Yet, offering a thorough insight on the mutual relationship between the indicators. Moreover, it quantifies the risk imposed from a certain event and temporally emulates the impact that can affect the system's behaviour. 


\section{Conclusion}

The sustainability of the engineering infrastructure, which is under the pressure of climate change, is vital. As a result, it is substantially important to continuously assess and appraise the existing infrastructure, for instance the reliability and resiliency of floodplain catchments, and ensure keeping the threatening impacts and risks tamed.

As a matter of fact, this paper is a continued work by the same authors to develop a novel approach on evaluating hydraulic risks raised by extreme floods [11]. The last paper focus was on the performance assessment application. However, in this paper the emphasis was on hydraulic simulation. Generally, the entire approach is integrating a 2-dimonsional hydraulic simulation with risk modelling in order to assess the performance of the system. This assessment can provide decision-makers, engineers and planners implications on the significance of the deriving factors that contribute to risk such as storm surges or mountainous flash floods that are caused by extreme rainfall. In addition, the approach suggests optimum safe zones for urban reclamation. Nevertheless, examine the adaptive capacity of the existing infrastructure in the case of extreme event. Moreover, provide inferences on either upgrade, modify, or disregard the catchment extents depending on the system's coping measures.

The focus of this study was to assist in the development of a simulation model that could predict and evaluate flood conditions and behaviour in the target area. It has merged management skills such as performance assessment, as well as technical skills such as hydraulic modelling to achieve the main aim of this study. It developed a consistent novel methodology for assessing the performance of a floodplain catchment on the Gold Coast, Australia temporally. The performance assessment of such infrastructure provides a detailed picture to decision makers on the status of the system. Moreover, this paper aimed to fill the gap of conveying an accurate visual estimation of the status of an infrastructure to the decision maker. Chances are decision-makers can better understand the whole picture of the system precisely, and undertake reliable decisions regarding adaptation strategies for the sustainability of engineering infrastructure.

\section{References}

[1] Abbs, D., The Effect of Climate Change on the Intensity of Extreme Rainfall Events. CSIRO Atmospheric Research. White Paper, 2004.

[2] Zhang, X., Wenfei, L. and Heling, X et al., Numerical simulation of flood inundation processes by $2 \mathrm{D}$ shallow water equations. Frontiers of Architecture and Civil Engineering in China. 1 (1): 107-113, 2007.

[3] Feyen, I., Vazquez, R. and Christiaens, K.et al., Application of a distributed physically-based hydrological model to a medium size catchment. Hydrology and Earth System Sciences. 4 (1): 47-63, 2000. 
[4] Simonovic, S. P., and Li, L., Methodology for Assessment of Climate Change Impacts on Large-Scale Flood Protection System. Journal of Water Resources Planning and Management, 129(5), 361-371, 2003.

[5] BARLAS, Y., Multiple tests for validation of system dynamics type of simulation models. European Journal of Operational Research, 42, 59-87, 1989.

[6] LANE, D. C., With a little help from our friends: how system dynamics and soft OR can learn from each other. System Dynamics Review, 10, 101-134, 1994.

[7] Google Inc., Google Earth [Online]. Available: http://www.google.com learth/index.html, 2012.

[8] Hashimoto, T., Stedinger, J. R., and Loucks, D. P., Reliability, resiliency, and vulnerability criteria for water resource system performance evaluation. Water Resour. Res., 18(1), pp. 14-20, 1982.

[9] Zongxue, X., Jinno, K., and Kawamura, A. et al., Performance Risk Analysis for Fukuoka Water Supply System. Water Resources Management. 12: 13-30, 1998.

[10] DHI GROUP, MIKE21 Flow Model Software [Online]. Available: http://www.dhigroup.com, 2011.

[11] Alsaqqaf, Z. and Zhang, H., Towards a sustainable system: application of temporal analysis on flood risk management. In: Brebbia, C. A. and Beriatos, E. (eds.) Sustainable Development and Planning V. Southampton: WIT Press, 2011. 